\title{
POISONINGS WITH STREET DRUGS: A REVIEW OF 1993-2008 DATA FROM THE TOXICOLOGY UNIT IN POLAND
}

\author{
ANNA KRAKOWIAK ${ }^{1}$, MALGORZATA KOTWICA ${ }^{2}$, and KONRAD ŚLIWKIEWICZ ${ }^{1}$ \\ ${ }^{1}$ Nofer Institute of Occupational Medicine, Łódź, Poland \\ Toxicology Unit, Department of Occupational Diseases and Toxicology \\ ${ }^{2}$ Nofer Institute of Occupational Medicine, Łódź, Poland \\ National Poison Information Centre
}

\begin{abstract}
Objective: Drugs of abuse have been known in many cultures and geographical zones, and also in Poland the extent of substance abuse has been increasing. Material and Methods: This report refers to patients treated for poisonings with street drugs at the Toxicology Unit (TU), Łódź, Poland during the period 1993-2008. The data to be analyzed was obtained from medical files of all patients treated for street drugs or hallucinogens abuse. Results: The kind of the drugs used has changed significantly; between 1993 and 1998 the majority of patients were opiate users, in 1999-2002 the dominant drug was amphetamine and in 2003-2008 there was recurrent increase in the number of opiate poisonings. Male patients were represented in the studied group more often than female ones. The percentages of patients treated after suicidal attempts ranged from $9.3 \%$ in 1993-1994 to 15.9\% in 2007-2008. During the analyzed period 1993-2008, cases of overdose were less frequent, while accidental intoxications became more common. Conclusions: Drug abuse is a serious problem in Poland, it has expanded in recent years and it is likely to expand further in the years to come. The treatment of drug-addicted people needs to be improved and a suitable prevention program should be developed.
\end{abstract}

Key words:

Poisonings, Street-drugs, Statistics, Łódź, Poland

\section{INTRODUCTION}

Progress of modern civilization which led to many impressive successes in such disciplines as medicine, physics or chemistry caused also negative effects, such as emotional strain and symptoms of frustrations experienced by a growing number of people. Drug addiction or alcoholism, quite frequent in the societies of developed countries, result from attempts to relieve those negative states by intake of psychoactive substances. The predominant addiction in Poland is alcoholism. However, recently there has been an increase in the number of persons dependent on street drugs, hallucinogens, somniferous drugs, tranquilizers or other psychoactives. Some features, describing the problem of addiction, have changed over the years. The use of psychoactive substances during the seventies was associated mostly with particular attitude towards life, searching for new life philosophy, joining popular movements rejecting the generally accepted ethical standards. During the nineties, it rather resulted from social misadaptation, feeling of loneliness and attempt to combat fears, escape from daily chores. At the same time, transformations in the national economy have caused that distribution of drugs in Poland has become very lucrative, while relevant legal regulations were quite incompatible with the changing social circumstances, and until the end of 1997 they had allowed some impunity for the persons involved in the distribution of street drugs.

Received: June 15, 2010. Accepted: November 16, 2010.

Address reprint requests to A. Krakowiak, Toxicology Unit, Department of Occupational Diseases and Toxicology, Nofer Institute of Occupational Medicine, św. Teresy 8 , 91-348 Łódź, Poland (e-mail: annakrak@imp.lodz.pl). 
The extent of drug addiction in Poland is difficult to assess. Some of the addicts are treated at detoxication units, others by toxicology centers, adolescents under fourteen years of age receive treatment at children hospitals, while those willing to be treated are referred to the rehab centers of MONAR - a non-governmental organization that helps people in difficult life circumstances, including alcohol and drug addicts. Unfortunately, the majority of addicts in Poland are left to themselves and do not receive any treatment, spending their time in the streets and pubs.

The aim of this paper is to report the frequency of poisonings with street drugs on the basis of the data collected during the period 1993-2008 by the Toxicology Unit (TU), Nofer Institute of Occupational Medicine (NIOM), Łódź, Poland.

\section{MATERIAL AND METHODS}

The data to be analyzed was obtained from medical files of all patients treated for street drugs or hallucinogens abuse between 1993 and 2008 at TU of the Department of Occupational Diseases and Toxicology, NIOM. This paper includes only patients aged 14 or older, because children under 14 are not treated at this unit. The selected group was additionally divided into subgroups according to the kind of substance used, namely opiates, amphetamine and its derivatives, Lysergic Acid Diethylamide (LSD), cocaine, cannabinoids, Datura sp. (Jimson weed), and hallucinogenic mushrooms.

The documents used by TU are prepared on the basis of standard medical notes and include the following data:

- duration of treatment ( $<6$ hours, $<24$ hours, number of days of hospital stay),

- patients' age and sex,

- kind of toxic agents with separately noted coingestion of alcohol,

- type of poisoning (intentional poisoning - suicidal attempt, abuse, criminal; unintentional poisoning accidental, occupational, chemical accident, fire, therapeutic error, overdose; others),
- kind of treatment (gastric lavage, antidotes, haemodialysis, peritoneal dialysis, haemoperfusion, haemofiltration, plasmapheresis, etc.),

- result of treatment (discharged home, deceased, transferred to another ward, etc.).

\section{RESULTS}

\section{Analysis of data on patients treated at TU} for intoxication by drugs and hallucinogens

Only 13 patients poisoned with drugs or hallucinogens $(\mathrm{D} / \mathrm{H})$ were treated at TU in 1993 (this accounted for $0.7 \%$ of all patients treated at TU in 1993), whereas in 2008, the number of patients treated there because of $\mathrm{D} / \mathrm{H}$ poisoning was $122(7.7 \%$ of the total number of patients) (Table 1). The kind of drugs used also changed significantly. Between 1993 and 1998 the majority of patients were opiate users, in 1999-2002 - amphetamine users, and in 2003-2008 there occured a recurrent increase in the number of patients poisoned with opiates (Table 2).

In 1993, only 2 patients after LSD use and 11 patients treated at TU for opiate intoxication (mainly extract from Papaver somniferum - poppy straw decoctions, known under the name of "Polish heroine") were found in the studied group (Table 2).

The first intoxication with amphetamine was recorded at the end of 1994, and from 1995 on a marked increase in the number of patients treated for this reason was observed (Figure 1). The proportion of patients intoxicated with amphetamine reached $55 \%$ of the total number of patients treated at TU for $\mathrm{D} / \mathrm{H}$ intoxication in 2000, from 2001 on there had been a falling trend, and in 2008 amphetamine-poisoned patients made up $13.5 \%$ (Figure 1). The proportion of poisonings with opiates, high in 1993-1994 (between $84.6 \%$ and $90 \%$ of all persons intoxicated with D/H), gradually fell during 1995-1997, with the minimum of $25.8 \%$ in 1999. Subsequently, it continued to rise until it finally reached $64.7 \%$ in 2008 (Figure 2). Opiate addicts hospitalized in 1993-1994 were intoxicated predominantly with morphine or Papaver somniferum straw extract (Table 2). Since 1995, a full range of psychoactive 
Table 1. Number of poisonings with substances of abuse in the city of Łódź, Poland, in 1993-2008

\begin{tabular}{lccc}
\hline & Year & Poisoned patients (total) & \multicolumn{2}{c}{ Patients poisoned with substances of abuse } \\
\cline { 2 - 4 } & $\mathrm{n}$ & $\mathrm{n}$ & $\%$ \\
\hline 1993 & 1804 & 13 & 0.72 \\
1994 & 1611 & 30 & 2.92 \\
1995 & 1807 & 49 & 3.59 \\
1996 & 1644 & 59 & 6.42 \\
1997 & 1604 & 103 & 7.36 \\
1998 & 1752 & 129 & 6.83 \\
1999 & 1815 & 124 & 7.45 \\
2000 & 2215 & 165 & 7.08 \\
2001 & 2471 & 175 & 6.30 \\
2002 & 2395 & 151 & 7.07 \\
2003 & 2232 & 158 & 7.38 \\
2004 & 2370 & 175 & 6.17 \\
2005 & 2654 & 161 & 5.10 \\
2006 & 1889 & 96 & 5.90 \\
2007 & 1244 & 74 & 7.70 \\
2008 & 1571 & 122 & \\
\hline
\end{tabular}

Table 2. Number of poisonings with substances of abuse according to the toxic agent in 1993-2008, Łódź, Poland

\begin{tabular}{|c|c|c|c|c|c|c|c|c|c|c|c|c|c|c|c|c|}
\hline \multirow{3}{*}{ Toxic agent } & \multicolumn{16}{|c|}{ Year } \\
\hline & 1993 & 1994 & 1995 & 1996 & 1997 & 1998 & 1999 & 2000 & 2001 & 2002 & 2003 & 2004 & 2005 & 2006 & 2007 & 2008 \\
\hline & \multicolumn{16}{|c|}{ poisonings with substances of abuse (n) } \\
\hline $\begin{array}{l}\text { Opiates (morphine, } \\
\text { heroine, codeine, "Polish } \\
\text { heroine", Tramadol) }\end{array}$ & 11 & 27 & 26 & 30 & 58 & 54 & 32 & 45 & 57 & 51 & 64 & 95 & 109 & 48 & 44 & 86 \\
\hline LSD & 2 & - & 2 & 3 & 2 & - & - & 1 & 1 & - & - & - & - & 1 & - & - \\
\hline Cocaine & - & 1 & 2 & 1 & - & 1 & - & 2 & - & 2 & 3 & 2 & - & 3 & 1 & - \\
\hline $\begin{array}{l}\text { Amphetamine and its } \\
\text { derivatives }\end{array}$ & - & 1 & 13 & 15 & 30 & 45 & 54 & 91 & 81 & 66 & 58 & 52 & 37 & 39 & 21 & 18 \\
\hline $\mathrm{THC}$ & - & 1 & 4 & 8 & 6 & 16 & 14 & 16 & 31 & 21 & 27 & 20 & 13 & 6 & 10 & 19 \\
\hline Datura stramonium & - & - & - & - & 7 & 5 & 2 & 2 & 2 & - & - & 1 & 1 & - & - & 8 \\
\hline $\begin{array}{l}\text { Hallucinogenic } \\
\text { mushrooms }\end{array}$ & - & - & - & - & - & - & 3 & 4 & - & 2 & - & 1 & - & 2 & - & - \\
\hline Other or unknown & - & - & 2 & 2 & 6 & 9 & 27 & 21 & 9 & 15 & 8 & 7 & 5 & 2 & 1 & 2 \\
\hline Total & 13 & 30 & 49 & 59 & $109^{*}$ & $130^{*}$ & $132 *$ & $182^{*}$ & $191^{*}$ & $157^{*}$ & $160^{*}$ & $178^{*}$ & $165^{*}$ & $101^{*}$ & $77^{*}$ & $133^{*}$ \\
\hline
\end{tabular}

* Since 1997 some patients were poisoned with two or more agents, mainly opiates and amphetamine or amphetamine and THC.

substances emerged in Poland, and TU-treated patients included users of cocaine, opiates, amphetamine, LSD and THC. The first intoxications with Datura sp. were observed in 1997, and in 1999 - with hallucinogen mushrooms. Only single cases of LSD or cocaine intoxication were noted during the whole studied period. 


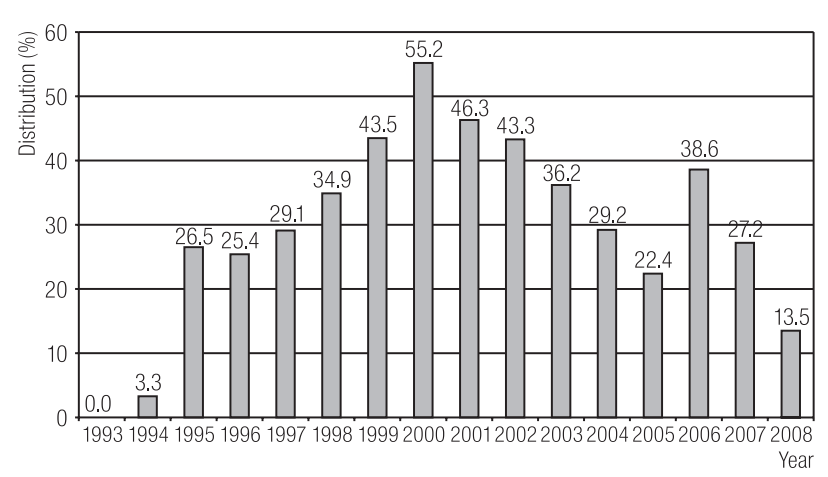

Fig. 1. Distribution of poisonings with amphetamine and its derivatives in 1993-2008, Łódź, Poland.

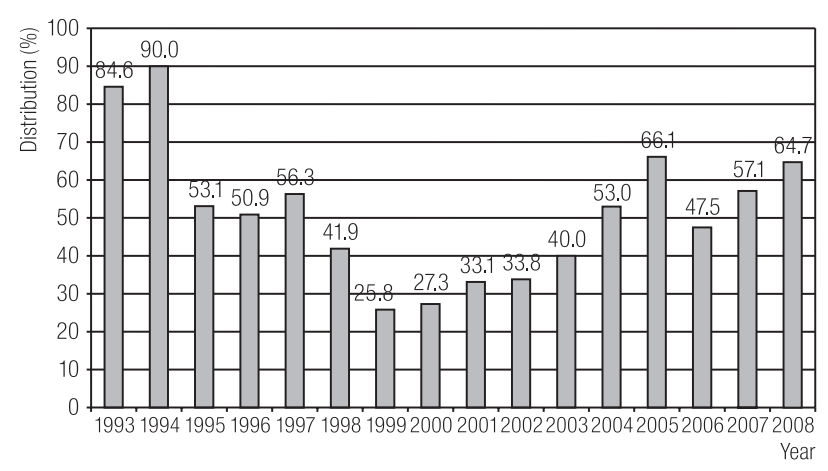

Fig. 2. Distribution of poisonings with opiates in 1993-2008, Łódź, Poland.

As for age, the largest groups were formed by patients between 21 and 30 years (44.2\%) and adolescents between 15 and 20 years $(29.7 \%)$ (Table 3 ).

In the age group 15-20, the use of amphetamine was the most common cause of admission to $\mathrm{TU}$, and the majority

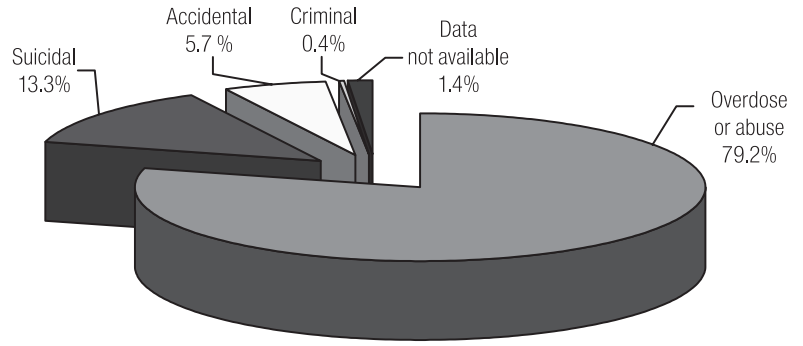

Fig. 3. Poisonings with substances of abuse by intent in 1993-2008, Łódź, Poland.

of THC and Datura intoxications were observed in that group (Table 3). Intoxications with hallucinogen mushrooms and opiates, in turn, constituted the most common cause for admission in the group 15-20 years (Table 3). During 1993-2002, the percentage of patients aged 15-20 steadily increased (from 16.3\% in 1993-1994 up to 39.9\% in 2001-2002), then it fell to $17.9 \%$, just to rise again up to $31.6 \%$ in 2007-2008 (Table 4). The proportion of patients from the age group of 21-30 year olds remained high throughout the whole examined period and ranged from 34.9\% in 1997-1998 to 53.7\% in 2005-2006 (Table 4). The percentage of patients between 31 and 40, however, fell markedly from $30.2 \%$ in $1993-1994$ to $8.2 \%$ in $2007-$ 2008 (Table 4). The patients above 40 formed the least numerous group, with the minimum of 5.6\% in 1995-1996 and the maximum of 10.8\% in 1997-1998 (Table 4).

Male patients were represented in the studied group more often than female ones (Table 5). During the analyzed

Table 3. Poisonings with substances of abuse by toxic agent and the patients'age in 1993-2008, Łódź, Poland

\begin{tabular}{lrrrrr}
\hline & \multicolumn{5}{c}{ Patients' age (years) } \\
\cline { 2 - 5 } \multicolumn{1}{c}{ Toxic agent } & $15-20$ & $21-30$ & $31-40$ & $>40$ & $\begin{array}{c}\text { data not } \\
\text { available }\end{array}$ \\
\cline { 2 - 5 } & 141 & 350 & 178 & 131 & 37 \\
\hline $\begin{array}{l}\text { Opiates (morphine, heroine, codeine, "Polish } \\
\quad \text { heroine", tramadol) }\end{array}$ & & & & 0 & 0 \\
LSD & 7 & 4 & 1 & 1 & 1 \\
Cocaine & 1 & 11 & 4 & 10 & 5 \\
Amphetamine and its derivatives & 233 & 318 & 49 & 6 & 2 \\
THC & 119 & 79 & 7 & 1 & 0 \\
Datura stramonium & 19 & 3 & 2 & 1 & 0 \\
Hallucinogenic mushrooms & 5 & 8 & 0 & 15 & 2 \\
Other or unknown & 33 & 46 & 13 &
\end{tabular}


Table 4. Distribution of poisoning with substances of abuse according to the patients' age in 1993-2008, Łódź, Poland

\begin{tabular}{|c|c|c|c|c|c|c|c|c|c|c|c|c|c|c|c|c|c|c|}
\hline \multirow{4}{*}{$\begin{array}{c}\text { Patients' } \\
\text { age } \\
\text { (years) }\end{array}$} & \multicolumn{18}{|c|}{ Period } \\
\hline & \multicolumn{2}{|c|}{ 1993-1994 } & \multicolumn{2}{|c|}{ 1995-1996 } & \multicolumn{2}{|c|}{ 1997-1998 } & \multicolumn{2}{|c|}{ 1999-2000 } & \multicolumn{2}{|c|}{ 2001-2002 } & \multicolumn{2}{|c|}{ 2003-2004 } & \multicolumn{2}{|c|}{ 2005-2006 } & \multicolumn{2}{|c|}{ 2007-2008 } & \multicolumn{2}{|c|}{ total } \\
\hline & \multicolumn{18}{|c|}{ distribution of poisoning with substances of abuse } \\
\hline & $\mathrm{n}$ & $\%$ & $\mathrm{n}$ & $\%$ & $\mathrm{n}$ & $\%$ & $\mathrm{n}$ & $\%$ & $\mathrm{n}$ & $\%$ & $\mathrm{n}$ & $\%$ & $\mathrm{n}$ & $\%$ & $\mathrm{n}$ & $\%$ & $\mathrm{n}$ & $\%$ \\
\hline $5-20$ & 7 & 16.3 & 32 & 29.6 & 69 & 29.7 & 103 & 35.6 & 135 & 39.9 & 80 & 24.1 & 46 & 17.9 & 62 & 31.6 & 534 & 29.7 \\
\hline $21-30$ & 17 & 39.5 & 49 & 45.4 & 81 & 34.9 & 115 & 39.8 & 138 & 40.8 & 165 & 49.5 & 138 & 53.7 & 91 & 46.4 & 794 & 44.2 \\
\hline $31-40$ & 13 & 30.2 & 19 & 17.6 & 44 & 19.0 & 40 & 13.8 & 27 & 8.3 & 41 & 12.3 & 44 & 17.1 & 16 & 8.2 & 244 & 13.7 \\
\hline$>40$ & 3 & 7.0 & 6 & 5.6 & 25 & 10.8 & 21 & 1. & 22 & 6.1 & 35 & 10.5 & 24 & 9.3 & 14 & 7.1 & 150 & 8.4 \\
\hline $\begin{array}{l}\text { Data not } \\
\text { available }\end{array}$ & 3 & 7.0 & 2 & 1.8 & 13 & 5.6 & 10 & 3.5 & 4 & 1.2 & 12 & 3.6 & 5 & 2.0 & 13 & 6.7 & 62 & 3.5 \\
\hline Total & 43 & 100.0 & 108 & 100.0 & 232 & 100.0 & 289 & 100.0 & 326 & 100.0 & 333 & 100.0 & 257 & 100.0 & 196 & 100.0 & 1784 & 100.0 \\
\hline
\end{tabular}

Table 5. Substances of abuse poisoning according to the patient's sex in 1993-2008, Łódź, Poland

\begin{tabular}{|c|c|c|c|c|c|c|c|}
\hline \multirow{3}{*}{ Year } & \multicolumn{6}{|c|}{ Sex } & \multirow{3}{*}{$\begin{array}{c}\text { Total } \\
\mathrm{n}\end{array}$} \\
\hline & \multicolumn{2}{|c|}{ male } & \multicolumn{2}{|c|}{ female } & \multicolumn{2}{|c|}{ data not available } & \\
\hline & $\mathrm{n}$ & $\%$ & $\mathrm{n}$ & $\%$ & $\mathrm{n}$ & $\%$ & \\
\hline 1993 & 12 & 92.3 & 1 & 7.7 & - & - & 13 \\
\hline 1994 & 23 & 76.7 & 6 & 20.0 & 1 & 3.3 & 30 \\
\hline 1995 & 40 & 81.6 & 8 & 16.3 & 1 & 2.1 & 49 \\
\hline 1996 & 44 & 74.6 & 14 & 23.7 & 1 & 1.7 & 59 \\
\hline 1997 & 72 & 69.9 & 30 & 29.1 & 1 & 1.0 & 103 \\
\hline 1998 & 98 & 76.0 & 29 & 22.5 & 2 & 1.5 & 129 \\
\hline 1999 & 76 & 61.3 & 42 & 33.9 & 6 & 4.8 & 124 \\
\hline 2000 & 110 & 66.7 & 49 & 29.7 & 6 & 3.4 & 165 \\
\hline 2001 & 125 & 71.4 & 47 & 26.9 & 3 & 1.7 & 175 \\
\hline 2002 & 107 & 70.9 & 40 & 26.5 & 4 & 2.6 & 151 \\
\hline 2003 & 115 & 72.8 & 35 & 22.1 & 8 & 5.1 & 158 \\
\hline 2004 & 125 & 71.4 & 48 & 27.4 & 2 & 1.2 & 175 \\
\hline 2005 & 124 & 77.0 & 32 & 19.9 & 5 & 3.1 & 161 \\
\hline 2006 & 69 & 71.9 & 23 & 23.9 & 4 & 4.2 & 96 \\
\hline 2007 & 53 & 71.6 & 18 & 24.3 & 3 & 4.1 & 74 \\
\hline 2008 & 81 & 66.4 & 33 & 27.1 & 8 & 6.5 & 122 \\
\hline Total & 1274 & 71.4 & 455 & 25.5 & 55 & 3.1 & 1784 \\
\hline
\end{tabular}

period they constituted $71 \%$ of all persons treated after $\mathrm{D} / \mathrm{H}$ use. However, the percentage of female patients treated at TU after drug abuse rose from 7.7\% in 1993 to $27.1 \%$ at the end of the observed period with the maximum of $33.9 \%$ in 1999 . The most common cause of hospitalization, in terms of the reason and way of intoxication, was overdose of $\mathrm{D} / \mathrm{H}(79.2 \%)$, followed by suicidal attempt (13\%), accidental poisoning (5.7\%) and criminal cases $(0.4 \%)$ (Figure 3$)$.

The percentage of patients treated after suicidal attempts ranged from $9.3 \%$ in $1993-1994$ to $15.9 \%$ in $2003-2004$ (Table 6). During the analyzed period 1993-2008, cases of overdose were fewer, while accidental intoxications became more frequent. 
Table 6. Type of poisoning with substances of abuse during the period 1993-2008, Łódź, Poland

\begin{tabular}{|c|c|c|c|c|c|c|c|c|c|c|c|c|c|c|c|c|c|c|}
\hline \multirow{4}{*}{$\begin{array}{c}\text { Type of } \\
\text { poisoning }\end{array}$} & \multicolumn{18}{|c|}{ Year } \\
\hline & \multicolumn{2}{|c|}{ 1993-1994 } & \multicolumn{2}{|c|}{ 1995-1996 } & \multicolumn{2}{|c|}{ 1997-1998 } & \multicolumn{2}{|c|}{ 1999-2000 } & \multirow{2}{*}{\multicolumn{2}{|c|}{$\begin{array}{c}\text { 2001-2002 } \\
\text { cases }\end{array}$}} & \multicolumn{2}{|c|}{ 2003-2004 } & \multicolumn{2}{|c|}{ 2005-2006 } & \multicolumn{2}{|c|}{$2007-2008$} & \multicolumn{2}{|c|}{ total } \\
\hline & & & & & & & & & & & & & & & & & & \\
\hline & $\mathrm{n}$ & $\%$ & $\mathrm{n}$ & $\%$ & $\mathrm{n}$ & $\%$ & $\mathrm{n}$ & $\%$ & $\mathrm{n}$ & $\%$ & $\mathrm{n}$ & $\%$ & $\mathrm{n}$ & $\%$ & $\mathrm{n}$ & $\%$ & $\mathrm{n}$ & $\%$ \\
\hline Suicidal & 4 & 9.3 & 12 & 11.1 & 33 & 14.2 & 32 & 11.1 & 41 & 12.6 & 53 & 15.9 & 32 & 12.5 & 30 & 15.3 & 237 & 13.3 \\
\hline $\begin{array}{l}\text { Overdose } \\
\text { or abuse }\end{array}$ & 39 & 90.7 & 94 & 87.0 & 187 & 80.6 & 235 & 81.3 & 264 & 81.0 & 233 & 69.9 & 208 & 80.9 & 153 & 78.0 & 1413 & 79.2 \\
\hline Accidental & - & - & 2 & 1.9 & 12 & 5.2 & 21 & 7.3 & 20 & 6.1 & 26 & 7.3 & 14 & 5.4 & 7 & 3.6 & 102 & 5.7 \\
\hline Criminal & - & - & - & - & - & - & 1 & 0.3 & 1 & 0.3 & 2 & 0.6 & 3 & 1.2 & - & - & 7 & 0.4 \\
\hline $\begin{array}{l}\text { Data not } \\
\text { available }\end{array}$ & - & - & - & - & - & - & - & - & - & - & 19 & 5.7 & - & - & 6 & 3.1 & 25 & 1.4 \\
\hline Total & 43 & 100.0 & 108 & 100.0 & 232 & 100.0 & 289 & 100.0 & 326 & 100.0 & 333 & 100.0 & 257 & 100.0 & 196 & 100.0 & 1784 & 100.0 \\
\hline
\end{tabular}

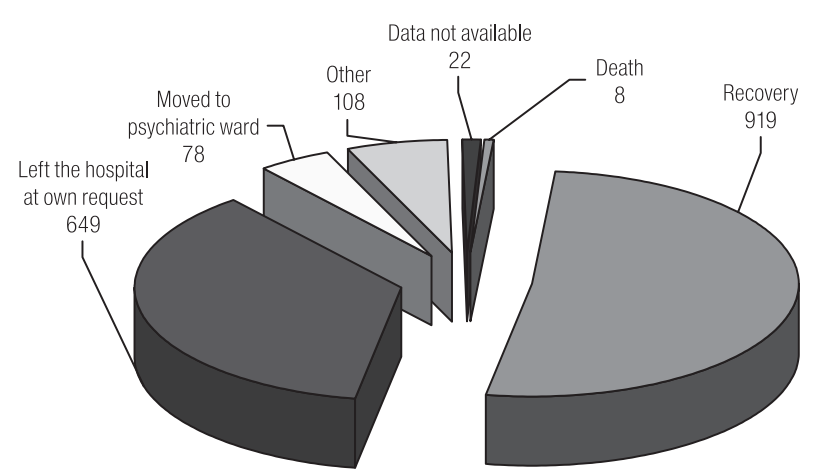

Fig. 4. Results of treatment in poisonings with substances of abuse in 1993-2008, Łódź, Poland

Only 8 patients died within the studied group during the analyzed period (Figure 4).

The final count of cases included 919 patients discharged home after completion of treatment, i.e. 649 patients discharged at their own request before completion of treatment, 78 patients transferred directly to psychiatric wards for further treatment, 108 patients transferred to other hospital wards and 8 deceased subjects. In 22 cases, data on the results of treatment was not available (the correct answer was not pointed by the physician in the document prepared for the National Poison Information Centre) (Figure 4).

\section{DISCUSSION}

The data obtained form medical histories of patients may be used to analyze the toxicological situation and trends. In our study, the information was collected from medical files of the patients treated at TU, Department of Occupational Diseases and Toxicology, NIOM, Łódź. TU provides medical treatment for all acute-poisoned patients in Łódź and its surroundings. The data obtained from those medical documents was analyzed by the National Poison Information Centre to map the toxicological situation.

The results of our study indicate that poisonings with opiates and psychoactive substances are still a common cause of admission to TU.

Between 1993 and 2008, the number of patients treated at TU for opiate or other psychoactive substance abuse has increased from $0.7 \%$ to $7.7 \%$ of the total number of patients.

A changing frequency of the abuse of opiates is perceivable during the period from 1993 to 2008; it increased systematically since 1993 (11 patients) to 1998 (54 cases). Following that, there was some transient decline in the opiates use, and since 2003 , the number of opiate poisonings has been rising again. A prospective cross-sectional study performed from April 1, 2003 until March 31, 2004 in Oslo revealed that the most frequent agents taken were: benzodiazepines (18\%), ethanol (17\%), paracetamol (12\%), opioids (7\%) and hydroxybutyric acid (7\%) [1]. Opioids and opiate products accounted for $54.02 \%$ of the cases of intoxication with non-pharmaceutical substances in the cross-sectional study including all patients aged 60 and older in Teheran from May 22 to November 21, 2003 [2]. 
Three patients (1.4\%) of 201 treated at the Poisoning Treatment Centre in Milan, included into the study on parasuicide and self-poisoning, took a substance of abuse (cocaine, heroin) or methadone [3].

When comparing the years 1999 and 2002, the use of amphetamines was the most common cause of hospitalization at TU $-43.5 \%$ and $43.3 \%$, respectively. Amphetamines proved to be the most frequent substances of abuse among the patients aged between 15 and 20 analyzed in our study. We also observed that amphetamine use was usually associated with certain recreational settings where young people spend free time. The same study reports the highest number of THC and Datura stramonium use in that group of hospitalized patients (119 and 19 patients, respectively).

The use of amphetamines in Norway is increasing according to the report published in 2007 [4]. Amphetamines are the most common illicit drugs in Europe according to the report published in 2009 by the European Monitoring Centre for Drugs and Drug Addiction (EMCDDA) [5].

The national survey data reported to the EMCDDA shows that in almost all EU countries the use of cannabis increased markedly during the 1990s, particularly involving young people and school students [5]. Other data indicates that over $1 \%$ of all European adults, namely about 4 million, use cannabis daily or almost daily. Most of these cannabis users, about 3 million, are aged between 15 and 34, representing approximately 2-2.5\% of all Europeans in this age group [6].

It is important to mention that Datura stramonium is most often used as hallucinogen by ingestion of the seeds or sometimes by smoking the leaves or drinking infusions prepared from the leaves. This anticholinergic plant contains tropane alkaloids, such as atropine, scopolamine and hyoscyamine [7].

We have also recorded the highest number of opiate and hallucinogenic mushroom use in the group aged between 21 and 30.

Data published by the EMCDDA estimates that the prevalence of the problem of opioid use in European countries during the period 2002-2007 ranges roughly between one and six cases per 1000 population aged 15-64 [5].
Our data corresponds to other studies, showing that opiate poisonings predominate mainly among the younger patients [8].

The group of patients poisoned with mushrooms included those treated after ingestion of mushrooms containing psilocybin (e.g. Psilocybe) or ibotenic acid and muscimol (Amanita muscaria). All hospitalized patients developed optical or auditory illusions and hallucinations.

Cocaine and LSD overdose among the patients treated at TU was rare.

The low number of cocaine-poisoned patients may be explained by a remarkably higher price of this toxic agent compared to other drugs. According to the EMCDDA report published in 2009 [5], in 2007 the mean retail price of cocaine ranged from EUR 44 to EUR 88 per gram. In comparison to this, the average retail price of cannabis resin, in 2007, ranged from EUR 3 to EUR 11 per gram in the 18 countries providing such information, while the average retail price of herbal cannabis ranged between EUR 1 and EUR 12 [5]. Ecstasy is now considerably cheaper than it was in the 1990s, when it first became widely available. While there are some reports of tablets being sold for less than EUR 2, most countries report average retail prices in the range of EUR 4-10 per tablet [5].

In the authors' opinion, limited availability of LSD is probably the main factor associated with low number of LSD poisonings noted in our study.

LSD retail prices have been slightly declining since 2003, and in 2007 the average value ranged between EUR 5 and EUR 12 per unit for the majority of reporting countries [5].

Males constituted the majority of the poisoned patients; however, the authors of the presented study noticed a rising tendency towards the use of opiates and psychoactive substances among women, from $7.7 \%$ in 1993 to $27.1 \%$ in 2008 .

Similar trend was also perceived in the Oslo study [1] where males used more illicit drugs, such as opioids and amphetamine than females.

We presume that the reasons for substance abuse by females may result from complex factors such as: biological 
predisposition, personal development, and social context (new trends in young females lifestyle).

In our study, overdose or abuse constituted the most frequent causes of poisoning with the analyzed agents (79.2\%). Suicidal poisonings were observed in $13.3 \%$ of the hospitalized patients. As most of these substances were regarded by the patients as recreational drugs, the intention of the intake was not suicidal.

We have noted 8 fatal cases of intoxication after the use of opiates or amphetamines.

There are publications indicating an increase in the rate of opioid-related deaths in many countries, such as Australia, Italy and United Kingdom during the last two decades [9-11]. The main cause of these deaths continues to be accidental fatal opioid overdose [9]. The opioid toxidrome that may develop after the use of opiates makes up a constellation of signs, including depression of mental status, ventilatory rate and tidal volume, miosis and reduced bowel motility. Most opioid-induced mortality relates directly to hypoxia [12].

Common features of amphetamine toxicity include tachycardia, dysrhythmias, hypertension, hyperthermia, agitation, delirium, seizures, hyperreflexia, diaphoresis, tachypnea, and rhabdomyolysis [13]. Death from amphetamine intoxication commonly results from hyperthermia, cardiac dysrhythmias, and intracerebral hemorrhage [14-16].

In our study, 78 patients were sent to psychiatric wards in the period from 1993 to 2008.

The aggressive and paranoid behavior is common after the use of psychoactive agents, so the patients presenting these symptoms should be sent to psychiatric hospitals. The patients after suicidal attempts, especially with previously diagnosed psychiatric problems, need the specific treatment in psychiatric wards as well.

In conclusion, data from toxicological units is often used to map toxicological trends; the incidence of opiates and psychoactive poisonings is still a common cause of admission to TU. These poisonings occurred more frequently among the males than the females. Most patients in our study survived without permanent post-drug abuse sequelae. Drug abuse is a serious problem in Poland, it has expanded recently and it is likely to expand further in the years to come. The treatment of drug addicted people needs to be improved and a suitable prevention program should be developed. The drug addict treatment system should comprise a network of units where patients could be detoxified and would receive psychiatric treatment, and a network of rehabilitation units preparing the patients for their new life.

\section{REFERENCES}

1. Hovda KE, Bjornaas MA, Skog K, Opdahl A, Drottning P, Ekeberg $\mathrm{O}$, et al. Acute poisoning treated in hospitals in Oslo: a one-year prospective study (1): Pattern of poisoning. Clin Toxicol 2008;46:35-41.

2. Karbakhsh M, Salehian Z. Pattern of poisoning in the elderly: an experience from Teheran. Clin Toxicol 2008;46:211-7.

3. Mauri MC, Cerveri G, Volonteri LS, Fiorentini A, Colasanti A, Manfre S, et al. Parasuicide and drug self-poisoning: Analysis of the epidemiological and clinical variables of the patients admitted to the Poisoning Treatment Centre (CAV), Niguarda General Hospital, Milan. Clin Pract Epidemiol Mental Health 2005;1(5):1-8.

4. United Nations Office on Drugs and Crime. 2007 world drug report [cited 2010 June 13]. United Nations Office on Drugs and Crime, Vienna. Available from URL: http://www.unodc. org/pdf/research/wdr07/WDR_2007.pdf.

5. European Monitoring Centre for Drugs and Drug Addiction, 2009. Amphetamines, ecstasy and hallucinogenic substances [cited 2010 June 13]. Available from URL: http://www. emcdda.europa.eu/publications/annual-report/2009.

6. European Commission. Young people and drugs among 15-24 year-olds [cited 2010 June 13]. Flash Eurobarometer 233, 2008b. Available from URL: http://ec.europa.eu/ health/ph_publication/eurobarometers_en.htm.

7. Burda P. Poisonous plants. In: Pach J, editor. An outline of clinical toxicology. Kraków: Wydawnictwo Uniwersytetu Jagiellońskiego; 2009. p. 574-94 [in Polish].

8. Bateman DN, Bain M, Gorman M, Murphy D. Changes in paracetamol, antidepressants and opioid poisoning in Scotland during the 1990s. QJM 2003;96:125-32.

9. Hall W, Darke S. Trends in opiate overdose deaths in Australia 1979-1995. Drug Alcohol Depend 1998;52:71-7. 
10. Davoli M, Perucci CA, Rapiti E, Bargagli AM, D’Ippoliti D, Forastiere $\mathrm{F}$, et al. Persistent rise of mortality of injecting drug users in Rome. Am J Public Health 1997;87:851-3.

11. Hall W, Lynskey M, Degenhardt L. Trends in opiate-related deaths in the United Kingdom and Australia, 1985-1995. Drug Alcohol Depend 2000;57:247-54.

12. Hahn IH, Nelson LS. Opioids. In: Brent J, Wallace KL, Burkhart KK, Phillips SD, Donovan JW. Critical Care Toxicology of the Critically Poisoned Patient. Philadelphia, Pensylvania: Elsvier Mosby Inc; 2005. p. 611-9.

13. McKinney PE, Palmer RB. Amphetamines and derivatives. In: Brent J, Wallace KL, Burkhart KK, Phillips SD,
Donovan JW. Critical Care Toxicology of the Critically Poisoned Patient. Philadelphia, Pensylvania: Elsvier Mosby Inc; 2005. p. 763-84.

14. Simpson DL, Rumack BH. Methylenedioxyamphetamine. Clinical description of overdose, death, and review of pharmacology. Arch Intern Med 1981;141:1507-9.

15. Kojima T, Une I, Yashiki M, Noda J, Sakai K, Yamamoto K. A fatal methamphetamine poisoning associated with hyperpyrexia. Forensic Sci Int 1984;24:87-92.

16. Logan BK, Weiss EL, Harruff RC. Case report: distribution of methamphetamine in a massive fatal ingestion. J Forensic Sci 1996;41:322-3. 